\title{
Phasic Dopamine Release Evoked by Abused Substances Requires Cannabinoid Receptor Activation
}

\author{
Joseph F. Cheer, Kate M. Wassum, Leslie A. Sombers, Michael L. A. V. Heien, Jennifer L. Ariansen, Brandon J. Aragona, \\ Paul E. M. Phillips, and R. Mark Wightman \\ Department of Chemistry and Neuroscience Center, University of North Carolina at Chapel Hill, Chapel Hill, North Carolina 27599-3290
}

Transient surges of dopamine in the nucleus accumbens are associated with drug seeking. Using a voltammetric sensor with high temporal and spatial resolution, we demonstrate differences in the temporal profile of dopamine concentration transients caused by acute doses of nicotine, ethanol, and cocaine in the nucleus accumbens shell of freely moving rats. Despite differential release dynamics, all drug effects are uniformly inhibited by administration of rimonabant, a cannabinoid receptor $\left(\mathrm{CB}_{1}\right)$ antagonist, suggesting that an increase in endocannabinoid tone facilitates the effects of commonly abused drugs on subsecond dopamine release. These time-resolved chemical measurements provide unique insight into the neurobiological effectiveness of rimonabant in treating addictive disorders.

Key words: rimonabant; dopamine; cocaine; nicotine; ethanol; cyclic voltammetry

\section{Introduction}

In 2004 alone, 21.1 million Americans were untreated for their addictions at a profound societal cost (Chou and Narasimhan, 2005). Recent insights into the neurobiology of abused drugs have advanced the development of potential therapeutic agents for at-risk individuals (O'Brien and Gardner, 2005). One of these, rimonabant [N-piperidino-5-(4-chlorophenyl)-1-(2,4dichlorophenyl)-4-methyl-pyrazole-3-carboxamide (SR141716A)]; Acomplia], $\mathrm{a} \mathrm{CB}_{1}$ receptor antagonist, attenuates many addictive behaviors (Arnold, 2005; Castane et al., 2005; Cohen et al., 2005; Colombo et al., 2005; Gardner, 2005). Emerging evidence indicates that the endocannabinoid system can interact with dopamine within the mesolimbic system, providing a candidate mechanism for the effects of rimonabant on addiction models (Hungund et al., 2003; Cheer et al., 2004; Cohen et al., 2005).

For almost two decades, it has been recognized that dopamine neurotransmission is critical in the reinforcing properties of addictive substances (Di Chiara and Imperato, 1988). Specifically, brain microdialysis studies showed that most abused drugs cause a prolonged increase in extracellular dopamine in the nucleus accumbens (NA). This finding, now commonly accepted, was initially surprising because the drugs studied act through very different pharmacological mechanisms. Recent chemical measurements with higher temporal resolution reveal that cocaine also induces highly dynamic dopamine concentration fluctuations that are superimposed on the prolonged rise in ambient levels (Heien et al., 2005). These dopamine fluctuations are highly important because they have been shown to accompany

Received July 18, 2006; revised Dec. 14, 2006; accepted Dec. 14, 2006

This work was supported by National Institutes of Health Grant DA 10900.

Correspondence should be addressed to R. Mark Wightman, Department of Chemistry and Neuroscience Center, Campus Box 3290, Venable Hall, University of North Carolina at Chapel Hill, Chapel Hill, NC 27599-3290. E-mail: rmw@unc.edu.

DOI:10.1523/JNEUROSCI.4152-06.2007

Copyright $\odot 2007$ Society for Neuroscience $\quad 0270-6474 / 07 / 270791-05 \$ 15.00 / 0$ reward seeking (Robinson et al., 2002b; Phillips et al., 2003; Roitman et al., 2004). Here, we show that other abused drugs also cause dopamine fluctuations in the NA and that the fluctuations are characteristic of the individual drugs. More importantly, even when induced with relatively high doses, we show that these fluctuations can be attenuated by rimonabant, establishing a role for cannabinoid receptors in the actions of abused drugs.

\section{Materials and Methods}

Animals and surgery. The procedures for voltammetric experiments in freely moving Sprague Dawley rats have been described previously (Heien et al., 2005). Rats ( $n=39 ; 250-350$ g; Charles River, Wilmington, MA), implanted with a jugular vein catheter, were surgically prepared $48 \mathrm{~h}$ before experiments. A guide cannula (BAS, West Lafayette, IN) to hold the microdrive for the carbon-fiber electrode was cemented in place above the NA shell (1.7 $\mathrm{mm}$ rostral, $0.8 \mathrm{~mm}$ lateral relative to bregma), and a bipolar stimulating electrode (Plastics One, Roanoke, VA) was permanently affixed in the ventral tegmental area (VTA) (1 mm lateral, $5.2 \mathrm{~mm}$ caudal, and $8.2 \mathrm{~mm}$ ventral from the surface of the brain). An $\mathrm{Ag} / \mathrm{AgCl}$ reference electrode was implanted in the contralateral hemisphere.

In vivo voltammetry. After recovery from surgery, a fresh cylindrical (length, $\sim 100 \mu \mathrm{m}$ ) carbon-fiber microelectrode was lowered into the NA shell of an awake rat using the microdrive secured into the guide cannula. Voltammetry used a triangular waveform $(-0.4$ to $+1.3 \mathrm{~V}$ vs a $\mathrm{Ag} / \mathrm{AgCl}$ reference) at $400 \mathrm{~V} / \mathrm{s}$, repeated every $100 \mathrm{~ms}$. Electrical stimulations delivered through the bipolar electrode (24 pulses; $2 \mathrm{~ms}$ each phase; $125 \mu \mathrm{A} ; 60 \mathrm{~Hz}$ ) were used to evoke dopamine and $\mathrm{pH}$ changes in the NA for use as the training set for principal component analysis (Heien et al., 2005). To optimize recording of transients, the electrode position was further adjusted to a location where spontaneous dopamine transients occurred with a frequency of $>1$ per minute. Once a recording site with transients was found, voltammograms were continuously collected. Naturally occurring dopamine transients were recorded for $15 \mathrm{~min}$, and this epoch is termed the baseline.

Dosing regimen. To evaluate the ways in which rimonabant modifies the effects of cocaine, ethanol, and nicotine on dopamine release, two groups of animals were compared for each abused drug. For cocaine and 
ethanol experiments, a within-subject regimen was used. First, saline was administered, followed $15 \mathrm{~min}$ later by the drug under study. Rimonabant was given 4.5 min later, and 28.5 min thereafter a second dose of the drug was administered. The control group was identical except vehicle was administered after the drug under study. Experiments with nicotine used a between-subject design. One group received vehicle, whereas the other received rimonabant. Nicotine was administered 4.5 min later.

Data analysis. After background subtraction, three-dimensional color plots of the voltammetric data were used to examine the responses as in supplemental Figure 1 (available at www. jneurosci.org as supplemental material). Dopamine changes were evaluated with principal component regression (Heien et al., 2005). This method allows dopamine concentration changes to be extracted from data at the $95 \%$ confidence level for epochs up to $90 \mathrm{~s}$ long. When evaluated for longer time periods, the residual becomes larger. However, rapid concentration changes, termed transients herein, can be extracted from multiple $90 \mathrm{~s}$ blocks allowing transient identification over many minutes. Mini Analysis (Synaptosoft, Decatur, GA) was used to determine the frequency, half-width, and amplitude of the dopamine transients. A fluctuation in the dopamine traces was deemed a transient if it was at least three times greater than the root mean square noise from data measured at a time when rapid chemical activity was not occurring. To determine the transient amplitude, the baseline was taken as the first minima located $0.3-0.6 \mathrm{~s}$ before the peak.

Both the amplitude and frequency of dopamine transients for each drug as well as the effects of rimonabant were analyzed using two-way ANOVA (repeated measures) for within-subject comparisons (cocaine and ethanol). Bonferroni's post hoc tests were used to assess between-subject differences when interactions [sample (cocaine/EtOH) and treatment (vehicle/rimonabant)] were significant, whereas Scheffé's post hoc tests were used to assess significant differences for within-subject comparisons. Student's $t$ tests for independent samples were used for between-subject (nicotine) comparisons. The criterion for significance was set at $p<0.05$. STATISTICA (StatSoft, Tulsa, OK) was used for statistical analyses.

Drugs. Cocaine $(3 \mathrm{mg} / \mathrm{kg}$ ) and nicotine $(0.3 \mathrm{mg} / \mathrm{kg}$ ) (both from SigmaAldrich, St. Louis, MO) were suspended in saline. Ethanol (Aaper Alcohol, Shelbyville, KY) was mixed in saline at $0.3 \mathrm{~g} / \mathrm{ml}$ and was administered at $1 \mathrm{~g} / \mathrm{kg}$. Rimonabant (SR141716A) (Research Triangle InstituteNational Institute on Drug Abuse, Raleigh, NC) was freshly suspended in a 1:1:18 ratio of ethanol, emulphor (Alkamuls EL-620; Rhodia, Cranbury, NJ), and heparinized saline $(0.9 \%)$. All drugs were administered intravenously through an indwelling jugular vein catheter.

\section{Results}

Extracellular dopamine after cocaine, nicotine, and ethanol Freely moving rats were placed in a behavioral chamber and the carbon-fiber electrode was placed in the NA at a site that exhibited spontaneous dopamine transients occurring at $>1$ per minute. After 15 min of baseline collection, they were administered $1 \mathrm{ml}$ of saline intravenously. This did not significantly alter the frequency or amplitude of dopamine transients, nor did it affect the dopamine steady-state concentration (vide infra). Cocaine $(3 \mathrm{mg} / \mathrm{kg})$, ethanol $(1 \mathrm{~g} / \mathrm{kg})$, or nicotine $(0.3 \mathrm{mg} / \mathrm{kg})$ were administered intravenously at doses demonstrated previously to have robust effects either on dopamine extracellular concentra- tions or behavior (Di Chiara and Imperato, 1988; Budygin et al., 2001; Robinson et al., 2002a; Heien et al., 2005; Matta et al., 2006).

As previously shown (Heien et al., 2005), extracellular dopamine concentration, extracted by principal component regression (supplemental Fig. 1, available at www.jneurosci.org as supplemental material), gradually increased and appeared to plateau during the $90 \mathrm{~s}$ observation time after $3 \mathrm{mg} / \mathrm{kg}$ cocaine $(n=5)$ (example in Fig. 1A, top panel). Superimposed on this gradual change were dopamine transients that are significantly greater in frequency (Fig. 1B) than after saline. Ethanol elicited more variable results $(n=9)$. In approximately one-half of the measurement sites, ethanol injection significantly increased transient frequency over control levels (Fig. $2 A$, top panel; $B, C$ ). Nicotine $(0.3 \mathrm{mg} / \mathrm{kg} ; n=4)$ caused a gradual increase in extracellular dopamine (Fig. $1 A$, right panel) that subsequently declined in the measurement interval. The timescale of this change is similar to that observed for regional cerebral blood flow in the rat nucleus accumbens with a similar dose (Gozzi et al., 2006). More frequent dopamine transients were superimposed on this response (Fig. $3 A$, top panel; $B)$.

Although all three abused drugs increased the frequency of dopamine transients, there were quantitative differences. With the doses used, the frequency of dopamine transients was increased most after cocaine ( $250 \%$ increase from saline) (Fig. $1 B$ ) followed by nicotine (181\% increase from saline) (Fig. $3 B$ ) and the ethanol-responsive sites (169\% from saline) (Fig. 2B). Whereas the amplitude of ethanol-evoked dopamine transients was unaltered, regardless of sampling site (Fig. 2C), the other two drugs increased transient amplitude compared with saline $(260 \%$ 


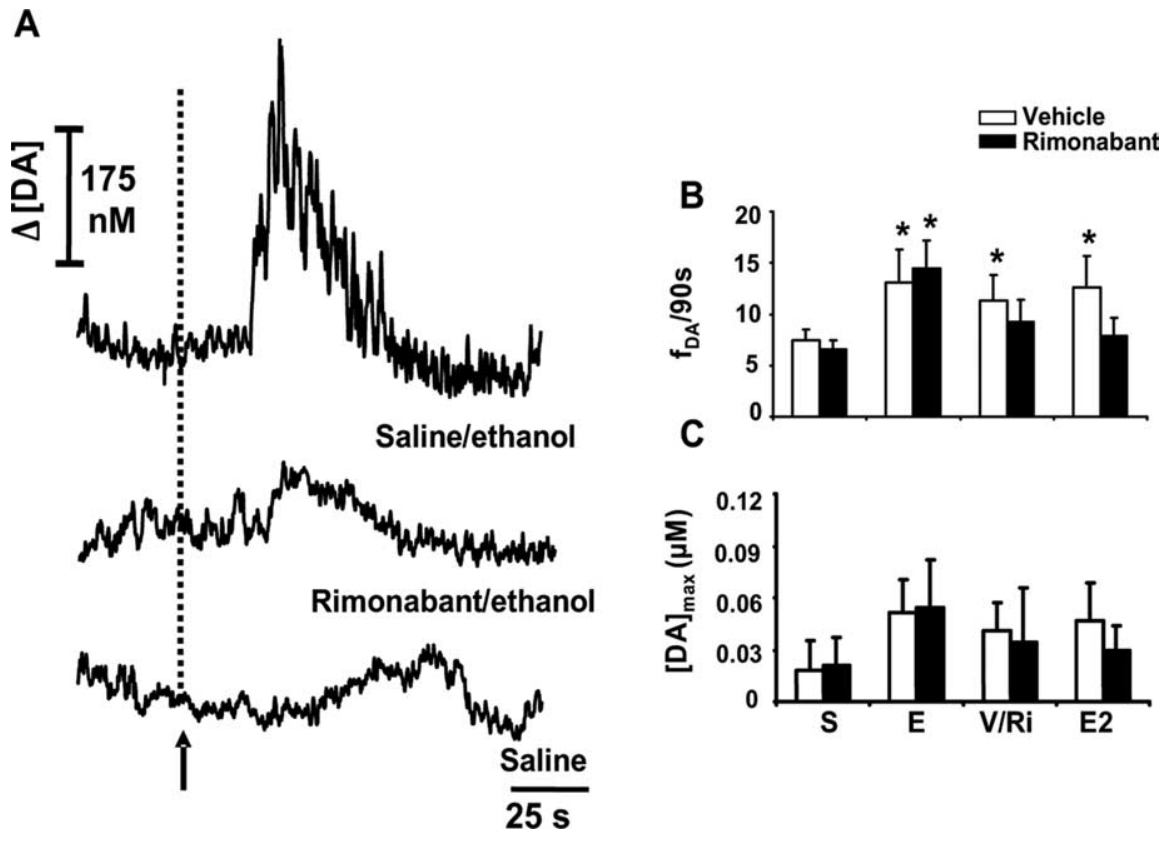

Figure 2. Cannabinoid receptor blockade attenuates the effects of ethanol of subsecond dopamine release. $\boldsymbol{A}$, Traces depicting ethanol-induced extracellular dopamine fluctuations after saline injection (top), the attenuation of this response by rimonabant after the second ethanol administration (middle) in the same animal and recording location, and the effects of saline injection at the same site (bottom). The arrow and dashed line indicate time of drug administration. $\boldsymbol{B}$, Pooled data from ethanol-responsive sites of the frequency of dopamine transients $\left(f_{D A}\right)$ in the $4.5 \mathrm{~min}$ after the end of each intravenous drug infusion (animals in the control group are shown in white bars). S, Saline; $E$, first dose of ethanol $(1 \mathrm{~g} / \mathrm{kg}) ; \mathrm{V} / \mathrm{Ri}$, vehicle $(n=8)$ or rimonabant $(n=9 ; 0.3$ $\mathrm{mg} / \mathrm{kg}$ ) injection $4.5 \mathrm{~min}$ after first dose of ethanol; E2, second dose of ethanol $(1 \mathrm{~g} / \mathrm{kg})$ given $30 \mathrm{~min}$ after vehicle or rimonabant (Scheffé's test, ${ }^{*} p<0.05$ compared with saline). C, Amplitude of drug-evoked dopamine transients ([DA $]_{\max }$ ). Error bars indicate SEM.

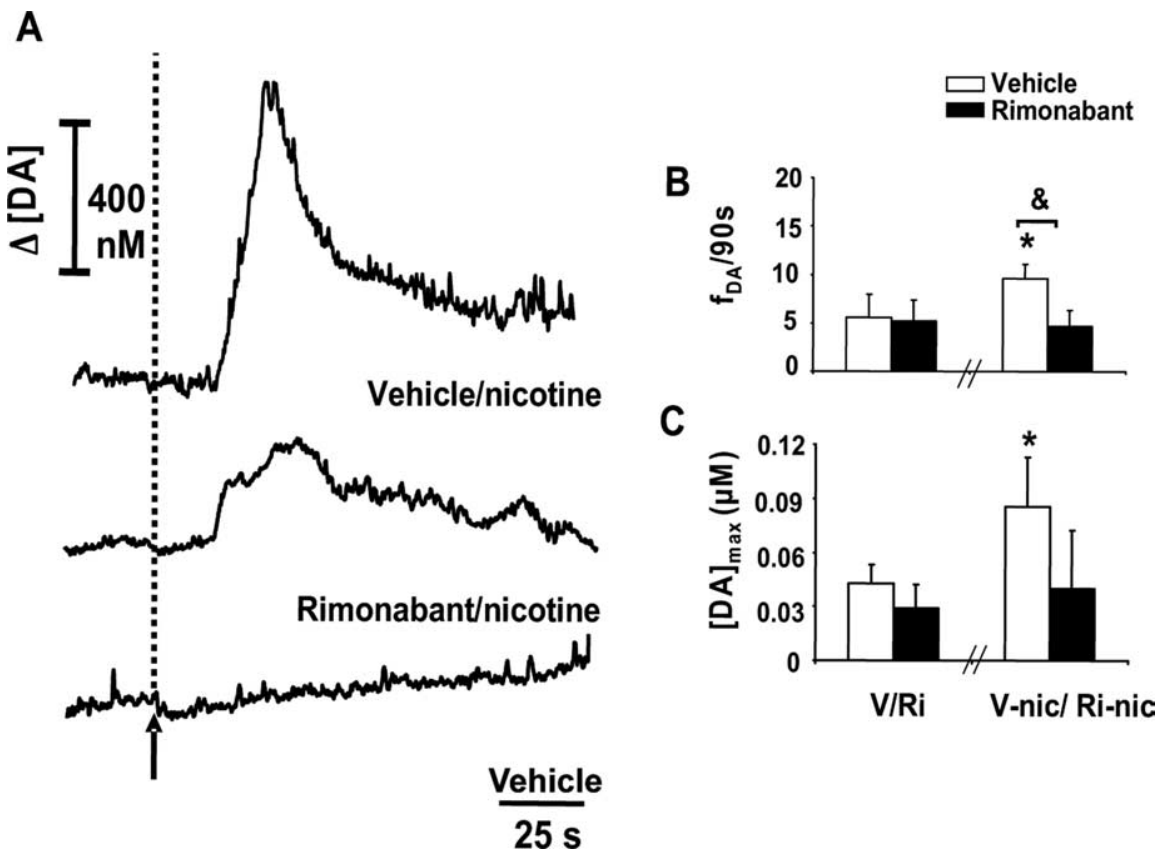

Figure 3. Nicotine elicits a potent dopamine spillover mediated by $C_{1}$ receptors. $A$, Dopamine trace showing the effects of nicotine injected after saline on subsecond dopamine release (top) and the dopamine response to nicotine when injected to a different animal in the presence of rimonabant (middle). The bottom panel shows the effects of vehicle injection (recorded from the same site as the trace shown in the top panel). The arrow and dashed line indicate time of drug administration. $\boldsymbol{B}$, Pooled data of the frequency of dopamine transients $\left(f_{\mathrm{DA}}\right)$ in the $4.5 \mathrm{~min}$ after the end of each intravenous drug infusion. V/Ri, Vehicle ( $n=$ 4) or rimonabant ( $n=4 ; 0.3 \mathrm{mg} / \mathrm{kg}$ ) injection; nicotine injection $(0.3 \mathrm{mg} / \mathrm{kg})$ given $4.5 \mathrm{~min}$ after vehicle (V-nic) or rimonabant (Ri-nic). (Student's t test, ${ }^{*} p<0.05$ compared with vehicle; ${ }^{*} p<0.05$, vehicle vs rimonabant-treated animals). $C$, Amplitude of drug-evoked dopamine transients $\left([D A]_{\max }\right)$. Error bars indicate SEM. after nicotine and $220 \%$ after cocaine) (Figs. 1C, 3C). Furthermore, the overall (steady-state and transient) increase in dopamine was twofold higher after nicotine compared with cocaine. The half-width of dopamine transients was significantly increased after cocaine (from $0.85 \pm 0.1$ to $1.4 \pm 0.2 \mathrm{~s} ; p<0.05)$, but it was unchanged after ethanol and nicotine. Additionally, whereas the cocaine and ethanol effects lasted beyond the interval shown, maximal nicotine effects on dopamine concentration were shorter-lived on average, probably because of receptor desensitization (Pidoplichko et al., 1997). Consistent with desensitization, no changes in dopamine release were seen after administration of a second dose of nicotine (data not shown).

Dopamine release induced by cocaine critically depends on $\mathrm{CB}_{1}$ receptor activation

A within-subjects design was used to test the effects of $\mathrm{CB}_{1}$ receptor blockade on subsecond dopamine release changes induced by cocaine (Fig. $1 A$, middle panel) obtained in the same animals as above (sample and treatment interaction, $F_{(3,21)}=$ 3.1; $p<0.05)$. Pooled data show that rimonabant given $4.5 \mathrm{~min}$ after cocaine significantly reduced the frequency of dopamine transients (Fig. $1 \mathrm{~B}$ ). A subsequent dose of cocaine $(3 \mathrm{mg} / \mathrm{kg}) 30 \mathrm{~min}$ after rimonabant (when the effects of the initial dose had subsided) did not significantly raise transient dopamine release above baseline levels (Fig. 1A, middle panel; $B$ ). Indeed, transient frequency after the second dose of cocaine in the presence of rimonabant was significantly lower than that induced by cocaine after saline (Fig. $1 B$ ) (sample, $F_{(3,21)}=11.7, p<0.0001$; $16.2 \pm 3.2$ vs $4.9 \pm 2.1$ transients per $90 \mathrm{~s}$; Scheffé's test, $p<0.05$ ). Rimonabant also reversed the increase in amplitude of dopamine transients after the first cocaine administration (Fig. 1C) and significantly prevented the rise in amplitude after the second dose of cocaine (Fig. $1 A$, middle panel; $C$ ) (sample, $F_{(3,21)}=3.3, p<0.05$; $77 \pm 9$ vs $39 \pm 5 \mathrm{~nm}$; Scheffé's test, $p<$ $0.05)$. No changes in transient frequency or amplitude were observed after vehicle injection $(n=4)$ (Fig. $1 B, C)$. Rimonabant did not alter the effects of cocaine on transient half-width as predicted by the lack of effect of the $\mathrm{CB}_{1}$ antagonist on dopamine uptake (Cheer et al., 2004). We also found a significant attenuation of cocaineinduced increases in locomotion by rimonabant $(n=5)$ (supplemental Fig. 2, available at www.jneurosci.org as supple- 
mental material), demonstrating a parallel functional consequence of disrupting endocannabinoid signaling.

\section{Endocannabinoid receptors control the effects of ethanol on rapid dopamine release}

The effects of rimonabant $(0.3 \mathrm{mg} / \mathrm{kg})$ on ethanol-evoked changes in dopamine were similarly assessed (Fig. $2 \mathrm{~A}$, middle panel) (sample and treatment interaction, $F_{(3,45)}=4.8 ; p<0.05$ ). In ethanol-responsive sites, rimonabant given $4.5 \mathrm{~min}$ after ethanol $(1 \mathrm{~g} / \mathrm{kg})$ significantly reversed the increase in the frequency of dopamine transients caused by ethanol administration (Fig. $2 B)$ and further prevented the effects of a subsequent dose (1 $\mathrm{g} / \mathrm{kg}$ ) given $30 \mathrm{~min}$ later, when the effects of the initial dose had subsided (Fig. $2 \mathrm{~A}$, middle panel; $C$ ) (sample, $F_{(3,45)}=8.5 ; p<$ $0.0001 ; 14.7 \pm 2.2$ vs $6.9 \pm 1.8$ transients per $90 \mathrm{~s}$; Scheffé's test, $p<0.05)$. Vehicle injection $(n=8)$ did not modify dopamine release after ethanol (Fig. $2 B, C$ ).

\section{Cannabinoid receptor blockade attenuates the subsecond dopaminergic response to nicotine}

Recent clinical trials (STRATUS-US) have shown that rimonabant $(20 \mathrm{mg}$ ) doubles smoking cessation rates for subjects motivated to quit compared with placebo (De Vries and Schoffelmeer, 2005). Thus, we examined the effects of rimonabant on the acute dopamine-releasing properties of nicotine. A betweensubject design to assess the effects of rimonabant $(0.3 \mathrm{mg} / \mathrm{kg})$ on nicotine-induced subsecond dopamine changes was used to avoid desensitization confounds. Rimonabant pretreatment prevented the nicotine-induced changes in frequency and amplitude of individual transients observed in vehicle controls $(n=4)$ and diminished the rise in area under the steady-state dopamine concentration trace (Fig. $3 A$, middle panel; $B, C$ ).

\section{Discussion}

This study confirms that pharmacologically distinct drugs of abuse usurp dopaminergic circuitry (Di Chiara and Imperato, 1988), but in strikingly different ways. Nicotine increases dopamine release as evidenced by increased transient frequency and amplitude; ethanol increases transient frequency, whereas cocaine amplifies dopamine transients by inhibiting its uptake. Remarkably, despite the mechanistic differences of these three drugs, rimonabant curtails the dopamine responses in each case. For all three drugs, the effects of rimonabant are attributable to an endocannabinoid-drug interaction because rimonabant alone does not affect transient frequency or amplitude in the NA (Cheer et al., 2004). Of particular interest is the suppression of drug-induced dopamine transients by rimonabant because these have been associated with drug seeking (Phillips et al., 2003) as well as acquisition of natural rewards (Roitman et al., 2004). Indeed, because the doses of abused drugs used in this study were quite high, it is remarkable that rimonabant was capable of modifying their effects on dopamine neurotransmission, both with respect to the gradual change and the dopamine transients.

The main action of cocaine on dopaminergic neurons is to inhibit the dopamine transporter. This action is apparent in our data as an increase in the half-width of the transients caused by an inhibition of the rate of uptake of released dopamine in the terminal regions. The apparent increased transient frequency after cocaine may be a direct consequence of this transporter blockade, which would render small transients more detectable (Heien et al., 2005). However, cocaine-induced changes in dopamine release critically depend on dopamine neuron activity (Nomikos et al., 1990), and several mechanisms have been identified that ex- plain how psychostimulants may increase the firing and bursting rates of VTA dopamine neurons under certain conditions (Lupica and Riegel, 2005). Nicotine acts on the dopaminergic system by increasing burst firing of mesolimbic dopaminergic neurons (Pidoplichko et al., 1997) and enhances dopamine release through calcium-dependent mechanisms (Turner, 2004). In our experiments, this modulation results in larger dopamine transients before desensitization occurs. Ethanol is known to increase the firing rate of dopaminergic neurons (Gessa et al., 1985), but decreases the amplitude of electrically evoked dopamine release (Budygin et al., 2001) without affecting the rate of dopamine uptake (Robinson et al., 2005).

Our findings complement many existing reports concerning dopamine and $\mathrm{CB}_{1}$ receptor interactions. For example, Cohen et al. (2005) found that nicotine, at a dose similar to that used here, elevated NA shell dopamine dialysate for at least $200 \mathrm{~min}$, and this was attenuated by rimonabant pretreatment. Nicotine binding induces much less desensitization of $\alpha 7$ subunits of nicotinic acetylcholine receptors (nAChRs) on glutamate terminals (Cohen et al., 2005) than of $\alpha 4 \beta 2$ nAChRs on GABAergic cells, resulting in prolonged excitatory input to dopamine cells. The long-lasting change observed with microdialysis may thus be attributable to $\alpha 7 \mathrm{nAChR}$ receptor activation, whereas the immediate changes in extracellular dopamine release seen with voltammetry may depend mostly on $\alpha 4 \beta 2$ nAChRs. Subsecond dopamine neurotransmission is thought to encode associative aspects of reinforcement (Schultz et al., 1997); therefore, the inhibition of nicotine-induced rapid dopamine release by rimonabant may underlie its ability to reduce cue-induced nicotine craving and dependence (Le Foll and Goldberg, 2005). This is especially important in nicotine abuse because the addition of cues has been shown to increase the number of infusions and the proportion of rats that acquire nicotine self-administration (Cohen et al., 2005). Similarly, smoking relapse in humans is highly dependent on environmental triggers (Le Foll and Goldberg, 2005).

Our findings after ethanol also concur with literature reports. Perra et al. (2005) demonstrated that rimonabant prevents and reverses ethanol-induced increases in dopamine neuron activity. Hungund et al. (2003) also showed that rimonabant attenuates the increase in dopamine release obtained with microdialysis. The modest effect of ethanol observed in those studies and in ours may be related to the lack of a specific signal transduction mechanism.

Whereas our results indicate that rimonabant can attenuate cocaine-induced increases in dopamine release, Soria et al. (2005) reported similar extracellular dopamine increases in wildtype and $\mathrm{CB}_{1}$ receptor-deficient mice, as well as in rimonabanttreated wild types compared with vehicle controls. However, that study used microdialysis and thus lacked the temporal resolution of the present results. Other factors such as species differences (mouse vs rat) and route of administration (intraperitoneal vs intravenous) may also account for the discrepancies. Soria et al. (2005) also showed that either $\mathrm{CB}_{1}$ receptor ablation or rimonabant treatment blunt cocaine self-administration. Our results are consistent with this observation because dopamine transients are critical for cocaine seeking (Phillips et al., 2003), and thus their inhibition, as shown here, would lead to deficits in the encoding and expression of the behavior. Furthermore, cannabinoid agonists promote cue-evoked reinstatement of cocaine seeking, responses mediated by dopamine transients (Phillips et al., 2003), and this is blocked by rimonabant (De Vries et al., 2001). 
With such different mechanisms of action, how does $\mathrm{CB}_{1}$ receptor blockade attenuate dopamine transients elicited by all three drugs tested? Endocannabinoids can be produced in various brain regions (Lupica and Riegel, 2005), and cannabinoids delivered to the NA and VTA are rewarding (Zangen et al., 2006). Because dopaminergic terminals lack cannabinoid receptors ( $\mathrm{Lu}-$ pica and Riegel, 2005), $\mathrm{CB}_{1}$ receptors located on presynaptic terminals in the VTA appear likely anatomical targets for the effects of rimonabant by preventing the binding of endocannabinoids produced from dopaminergic neurons in the VTA (the origin of the projection to the NA). Indeed, presynaptic $\mathrm{CB}_{1}$ receptors on GABA and glutamatergic terminals in the VTA can modulate dopamine neuron firing (Szabo et al., 2002; Lupica and Riegel, 2005). The attenuation of drug-induced dopamine activity shown here suggests that rimonabant antagonizes a signaling pathway involving a preferential endocannabinoid-mediated inhibition of GABA release onto dopamine neurons (Szabo et al., 2002; Riegel and Lupica, 2004). This interaction between GABA and endocannabinoids may not only involve the actions of drugs of abuse belonging to different pharmacological classes, but may also encompass the properties of more natural addictions such as overeating (Di Marzo and Matias, 2005), a pathology that is ameliorated by rimonabant. Thus, our findings support the usefulness of a single approach to the treatment of addictions to multiple drugs of abuse and possibly to natural rewards.

\section{References}

Arnold JC (2005) The role of endocannabinoid transmission in cocaine addiction. Pharmacol Biochem Behav 81:396-406.

Budygin EA, Phillips PE, Robinson DL, Kennedy AP, Gainetdinov RR, Wightman RM (2001) Effect of acute ethanol on striatal dopamine neurotransmission in ambulatory rats. J Pharmacol Exp Ther 297:27-34.

Castane A, Berrendero F, Maldonado R (2005) The role of the cannabinoid system in nicotine addiction. Pharmacol Biochem Behav 81:381-386.

Cheer JF, Wassum KM, Heien ML, Phillips PE, Wightman RM (2004) Cannabinoids enhance subsecond dopamine release in the nucleus accumbens of awake rats. J Neurosci 24:4393-4400.

Chou IH, Narasimhan K (2005) Neurobiology of addiction. Nat Neurosci 8:1427.

Cohen C, Kodas E, Griebel G (2005) CB1 receptor antagonists for the treatment of nicotine addiction. Pharmacol Biochem Behav 81:387-395.

Colombo G, Serra S, Vacca G, Carai MA, Gessa GL (2005) Endocannabinoid system and alcohol addiction: pharmacological studies. Pharmacol Biochem Behav 81:369-380.

De Vries TJ, Schoffelmeer AN (2005) Cannabinoid CB1 receptors control conditioned drug seeking. Trends Pharmacol Sci 26:420-426.

De Vries TJ, Shaham Y, Homberg JR, Crombag H, Schuurman K, Dieben J, Vanderschuren LJ, Schoffelmeer AN (2001) A cannabinoid mechanism in relapse to cocaine seeking. Nat Med 7:1151-1154.

Di Chiara G, Imperato A (1988) Drugs abused by humans preferentially increase synaptic dopamine concentrations in the mesolimbic system of freely moving rats. Proc Natl Acad Sci USA 85:5274-5278.

Di Marzo V, Matias I (2005) Endocannabinoid control of food intake and energy balance. Nat Neurosci 8:585-589.

Gardner EL (2005) Endocannabinoid signaling system and brain reward: emphasis on dopamine. Pharmacol Biochem Behav 81:263-284.

Gessa GL, Muntoni F, Collu M, Vargiu L, Mereu G (1985) Low doses of ethanol activate dopaminergic neurons in the ventral tegmental area. Brain Res 348:201-203.

Gozzi A, Schwarz A, Reese T, Bertani S, Crestan V, Bifone A (2006) Region- specific effects of nicotine on brain activity: a pharmacological MRI study in the drug-naive rat. Neuropsychopharmacology 31:1690-1703.

Heien ML, Khan AS, Ariansen JL, Cheer JF, Phillips PE, Wassum KM, Wightman RM (2005) Real-time measurement of dopamine fluctuations after cocaine in the brain of behaving rats. Proc Natl Acad Sci USA 102:10023-10028.

Hungund BL, Szakall I, Adam A, Basavarajappa BS, Vadasz C (2003) Cannabinoid CB1 receptor knockout mice exhibit markedly reduced voluntary alcohol consumption and lack alcohol-induced dopamine release in the nucleus accumbens. J Neurochem 84:698-704.

Le Foll B, Goldberg SR (2005) Control of the reinforcing effects of nicotine by associated environmental stimuli in animals and humans. Trends Pharmacol Sci 26:287-293.

Lupica CR, Riegel AC (2005) Endocannabinoid release from midbrain dopamine neurons: a potential substrate for cannabinoid receptor antagonist treatment of addiction. Neuropharmacology 48:1105-1116.

Matta SG, Balfour DJ, Benowitz NL, Boyd RT, Buccafusco JJ, Caggiula AR, Craig CR, Collins AC, Damaj MI, Donny EC, Gardiner PS, Grady SR, Heberlein U, Leonard SS, Levin ED, Lukas RJ, Markou A, Marks MJ, McCallum SE, Parameswaran N, et al. (2006) Guidelines on nicotine dose selection for in vivo research. Psychopharmacology (Berl), in press.

Nomikos GG, Damsma G, Wenkstern D, Fibiger HC (1990) In vivo characterization of locally applied dopamine uptake inhibitors by striatal microdialysis. Synapse 6:106-112.

O'Brien CP, Gardner EL (2005) Critical assessment of how to study addiction and its treatment: human and non-human animal models. Pharmacol Ther 108:18-58.

Perra S, Pillolla G, Melis M, Muntoni AL, Gessa GL, Pistis M (2005) Involvement of the endogenous cannabinoid system in the effects of alcohol in the mesolimbic reward circuit: electrophysiological evidence in vivo. Psychopharmacology (Berl) 183:368-377.

Phillips PE, Stuber GD, Heien ML, Wightman RM, Carelli RM (2003) Subsecond dopamine release promotes cocaine seeking. Nature 422:614-618.

Pidoplichko VI, DeBiasi M, Williams JT, Dani JA (1997) Nicotine activates and desensitizes midbrain dopamine neurons. Nature 390:401-404.

Riegel AC, Lupica CR (2004) Independent presynaptic and postsynaptic mechanisms regulate endocannabinoid signaling at multiple synapses in the ventral tegmental area. J Neurosci 24:11070-11078.

Robinson DL, Brunner LJ, Gonzales RA (2002a) Effect of gender and estrous cycle on the pharmacokinetics of ethanol in the rat brain. Alcohol Clin Exp Res 26:165-172.

Robinson DL, Heien ML, Wightman RM (2002b) Frequency of dopamine concentration transients increases in dorsal and ventral striatum of male rats during introduction of conspecifics. J Neurosci 22:10477-10486.

Robinson DL, Volz TJ, Schenk JO, Wightman RM (2005) Acute ethanol decreases dopamine transporter velocity in rat striatum: in vivo and in vitro electrochemical measurements. Alcohol Clin Exp Res 29:746-755.

Roitman MF, Stuber GD, Phillips PE, Wightman RM, Carelli RM (2004) Dopamine operates as a subsecond modulator of food seeking. J Neurosci 24:1265-1271.

Schultz W, Dayan P, Montague PR (1997) A neural substrate of prediction and reward. Science 275:1593-1599.

Soria G, Mendizabal V, Tourino C, Robledo P, Ledent C, Parmentier M, Maldonado R, Valverde O (2005) Lack of CB1 cannabinoid receptor impairs cocaine self-administration. Neuropsychopharmacology 30:1670-1680.

Szabo B, Siemes S, Wallmichrath I (2002) Inhibition of GABAergic neurotransmission in the ventral tegmental area by cannabinoids. Eur J Neurosci 15:2057-2061.

Turner TJ (2004) Nicotine enhancement of dopamine release by a calciumdependent increase in the size of the readily releasable pool of synaptic vesicles. J Neurosci 24:11328-11336.

Zangen A, Solinas M, Ikemoto S, Goldberg SR, Wise RA (2006) Two brain sites for cannabinoid reward. J Neurosci 26:4901-4907. 